\title{
The Pedagogical Innovation Serving Technological Education
}

\author{
Sameh Ben Hamida' ${ }^{1}$ Alia Maaloul ${ }^{1}$, Sana Ben Hamida ${ }^{2}$ \\ ${ }^{1}$ Institute of Higher Technological Studies of Gabes, Gabes, Tunisia \\ ${ }^{2}$ Institute of Higher Technological Studies of Nabeul, Nabeul, Tunisia \\ Email:Benhamida_sameh@yahoo.fr,maaloul.alia@gmail.com,Sana_benhamida@yahoo.fr
}

Received 4 December 2015; accepted 17 January 2016; published 20 January 2016

Copyright (C) 2016 by authors and Scientific Research Publishing Inc.

This work is licensed under the Creative Commons Attribution International License (CC BY). http://creativecommons.org/licenses/by/4.0/

c) (i) Open Access

\begin{abstract}
It is now recognized that the learner is no longer passive, he becomes the main actor of his training. There are, in fact, the part of the learner, an appropriation work that is taking place and the trainer, a specific work to promote learning. In order to offer to our students a better education, we began to discover some techno approaches crossing innovative teaching and set up two educational modalities that we experienced in Institute of Higher Technological Studies IHTS of Gabes for the students having speciality of telecommunications and networking by the introduction of flipped classroom and serious games. This was followed by a comparison of different pedagogical approaches tested to detect their contributions and limitations.
\end{abstract}

\section{Keywords}

Pedagogical Innovation, Serious Games, Flipped Classroom, Motivation

\section{Introduction}

With regards of current changes in education, for example, the extension of the public, the diversification of its characteristics as the abundance of new technologies and the need to develop new skills among students, etc., innovation becomes almost necessary to meet the challenges of this context (Poumay, 2014).

According to a study by Emilie Tremblay-Wragg \& Carole Raby (2014), we must change the learning situations. In fact, they have given five reasons why university teacher should diversify teaching models which are the following:

- All cannot learn in the same way (Legendre, 2004);

- The teacher should opt for a flexible repertoire of actions and intentions (Pratt, 2005); 
- Prolonged use of the same teaching model produces a saturation effect in students (Joyce, Weil, \& Calhoun, 2004, quoted in Legendre, 2005).

- In order to allow the transfer of learning, students must be in the presence of numerous and varied situations (Meirieu, Develay, Durand, \& Mariani, 1996).

- The possibility of using different educational models allows flexibility and adjustment to changes in the concrete situations of teaching and learning (Joyce et al., 2004, cited in Legendre, 2005)

In this work, we have tried to diversify teaching strategies to identify the contributions and limitations of each of them according to the characteristics of the subjects taught. Indeed, we have experienced the flipped classroom and serious games. In what follows, we will first review the main approaches and teaching strategies, and then we will present the different strategies that we have tested. After that, we present our comparative study in order to identify the contributions and limitations of each strategy tested.

\section{Context and Issues}

This work falls within the scope of experimentation of active learning in the IHTS of Gabes in a set of materials dedicated to the students of Science Technology of Information and Communication (STIC) department at different levels, namely, the use of serious game "BD-GAME" in the Database course for students of the second year during a semester and flipped classroom experimentation provided to students of the third year at DBMS course's for a semester also.

The objective of this experiment is to promote the learning of our students through the use of new techno pedagogical approaches and to make a comparative study between two approaches and to identify the strengths and weaknesses of each of each one. Through this study, we will try to answer some questions, namely:

- In what extent the introduction of new techno pedagogical means it promotes learning for students?

- How to make students active and involved in their learning?

- Is it that one can speak of a better educational approach?

Approaches to active learning have in common to empower students to improve learning. So you could say that the objective of the use of active learning is to motivate our students and involve them more in the process of learning.

Recourse to the use of active learning is a result of observations made in our students who are increasingly uninterested in lectures and by the so-called conventional methods. As noted, following the course of the previous sessions, a distinct lack of motivation that causes a lack of commitment (Viau, 2006), a lack of performance and passivity of students in the sessions Tutorials and Practical work. However, that population has a considerable incentive to video games and to using the Internet.

\section{Overview of the Main Approaches and Teaching Strategies}

As highlighted Bédard \& Béchard (2009) (cited by Poumay, 2014), innovating pedagogy should ideally mean "seek to substantially improve the learning of students interaction situation".

It was in this effort to improve the teaching has evolved embodied in a transition through a set of pedagogical approaches with different characteristics that will be presented in the next section.

The first approach which is the traditional teaching is that of the customary pattern. According to the educational triangle of Jean Houssaye it is the knowledge side and it favors the teaching approach of the teacher. This classic approach is that of knowledge, model, authority, effort, individualism and punishment.

As a second approach includes the differentiated pedagogy that starts from the observation that in a classroom, a teacher has to teach students with very different abilities and learning modes, she tries to give an answer to this heterogeneity of classes with practical adapting to each student curriculum, teaching and schools. Often the teacher will no longer be the center of the class but will put the child or the activity as a central concern.

This approach is the cornerstone of the Active pedagogy aimed to make the student the actor of learning, so that build his knowledge through research situations. Active learning refers historically to Adolphe Ferriere who at the beginning of the twentieth century, was among the first to use the term active school in its publications. It is one of the bases of the Current New Education.

Today, we tend to wrongly classified under the term active methods all methods that actually involve the student with exercises or simulations, such practices that triggered another approach that matches the project teaching that puts learning through the realization of a concrete production. The project can be individual (presenta- 
tion, layout) or collective (organization of a festival, travel, entertainment). It is a "modality that allows a group of students to carry out a concrete production socializable, integrating new knowledge".

Also include the approach to pedagogy is based on the concepts of social constructivism and motivation based on the idea that the acquisition of lasting knowledge is favored by the inclusion of the social field in which it is located. This theory was developed by Lev Vygotsky, based on Piaget's constructivism.

By another route, Pedagogy of "build knowledge through documents" aims several objectives. First documentary pedagogy means the autonomy of the student. Indeed, the student does not expect that issue to know, he will himself be appropriated by seeking information in documents, and returning it according to his expectations, needs. Documentary pedagogy also involves the development of critical thinking of students as learning with documents, is learning to validate the information, learn to recognize the relevance of a document with respect to increased windfall with documentary development of information and communications technology. Finally, documentary pedagogy is the immediate objective tool used by a student resource center.

Beyond these approaches, we can also cite Problem-Based Learning. PBL where learners, grouped by teams, working together to solve a problem-usually proposed by the teacher, the problem for which they have not received any special training, so make learning content and to develop problem solving skills. The task of the team is usually to explain the phenomena underlying the problem and try to solve it in a non-linear process. The approach is guided by the teacher acts as a facilitator or mediator (Panis, 2009)

Through these approaches, the teacher in the new era of education should consider the following parameters: the approach and strategy to use, teaching technique, strengths, weaknesses, manipulative, student interest, terminal skills to develop and learning evaluation method. These decisions are critical and must be taken knowingly.

An effective teacher does not use the same set of practices for each course... However, he constantly thinks about his work, observes her students whether they learn or not and adjusts its teaching practice accordingly.

To this end, it would be unrealistic to believe that one method would be most adapted to education. It is therefore for the teacher to apply adequate pedagogical strategy and optimum for the use of these different approaches.

In this context the pedagogical strategy is considered a "General Plan as a set of operations arranged to support the achievement of a goal. In this case the pedagogical strategy consists of integrating principle that describes the outline and a scenario of a learning event which explains the layout and joint operations (Paquette et al., 1998).

According to a description of the teaching strategies of Basque (2007), the list of these strategies includes the following:

- Conference, Debate, Guided discovery, demonstration, Team teaching; Modular teaching, teaching individual prescription; Personalized education; Programmed instruction, Interview, Case Study, Peer Review, Exercise, Lecture, discussion Group (symposium, plenary session hubbub, square root, rotating, debate, panel, brainstorming), Game, educational game; simulation game, Role Play, Laboratory, Guided Reading, Personal Portals, Digital Portfolio, Presentation, Multimedia Production, Project, Publication, Web Search, Search databases, Problem Solving, Simulation, internship, teleconference, tournament, team work, etc.

To this list we can add the flipped classroom and serious games which will be detailed in the next section on implementation at our institution raises several questions: target competencies, integration in the curriculum, methods of use, ownership by learners, assessment methods, etc.

\section{Adopted Methodology}

The methodological approach adopted as part of this work consists of qualitative and quantitative data analysis.

Our approach was as following:

- A qualitative study to identify the variables involved in assessing the quality of training in the two educational systems implemented and experienced in serious games and flipped classroom based on bibliographical research and daily observations.

- A quantitative study of the behavior, expectations or opinions of our students on our experienced devices to complement the qualitative study.

The questionnaire was the adopted technique. Questionnaires were exhaustively addressed to students and interviews were conducted with the evaluator teachers. For the development of evaluation questionnaires, we fol- 
lowed the model of Kirkpatrick (2007), composed of four levels:

- Participant satisfaction;

- Achievements of the participants;

- Changes perceptible practices;

- Changes in the organization visible.

It should also be noted that the two experiments subject of this work is based on social constructivism as reference pedagogical model. The construction of knowledge, although it is personal, is done in a social setting. This model puts the learner at the center of the learning act and promotes autonomy of learning as well as exchanges tutor-learner and especially learner-learner.

\section{Experimentation}

\subsection{Experiment 1: Teaching through Serious Games}

\subsubsection{Definition}

Serious Games is software that combines intention "serious"-kind educational, informative, communicative, marketing, ideological or training-with playful processes. These games have utility applications in various sectors: education, health, communication, politics, defense, etc. As part of Database course, we chose to create and use Serious Games.

\subsubsection{Motivation, Context and Target Audience}

The leitmotif of this experience is a combination of technical and pedagogical aspects to develop a new educational tool for teaching and self-evaluation in IHTS of Gabes: serious gaming BD-GAME is an innovative tool allowing the student to take store of their learning and test their knowledge databases.

It is in this context and for the second level students during database course at IHTS of Gabes that we chose to move away from traditional teaching methods and position ourselves in a renewed approach teaching to design, develop and provide our students with a serious game called BD-GAME to enrich the education provided.

\subsubsection{Objectives}

The introduction of the Serious Game in our current educational tool seems to enrich the education provided and motivate students through the use of mechanical activities drawn from the world of video games, which universe has developed in recent decades, very sophisticated strategies to motivate players to progress in virtual worlds and submit it to their exploration (Sanchez et al., 2011).

The educational objectives that we have set are:

- The acquisition of skills;

- The discovery of new concepts;

- And the consolidation of concepts exposed previously.

\subsubsection{Teaching Device}

The project resulted in a semester by the establishment in April 2015 of a serious online game called BD-GAME developed with Ludiscape software, the home screen is shown in Figure 1:

It consists of three modules:

- Module 1 on the subject of general information on databases that consists of a first part having all the theoretical concepts on databases namely their definition, their characteristics, their contributions compared to files and systems database management and functionality in order to introduce the current data bases.

- Module 2 themed Model Entity/association and the relational model consist of a theoretical part even with all the theoretical concepts that are related followed by a summary and exercises.

- Module 3 on the theme of the SQL language consists of a theoretical part presenting the different commands of this language with exercises.

Each theoretical part is followed by a summary and exercises.

In addition, we point out that we have built in this serious game a set of attractive and most funny characters which explains the success of this experiment.

For details, this game is available online from the following link:

http://www.cloudlearning.fr/datacloud/jeuserieuxpourlenseignementdecoursdebasesdedonnees0727723/ 


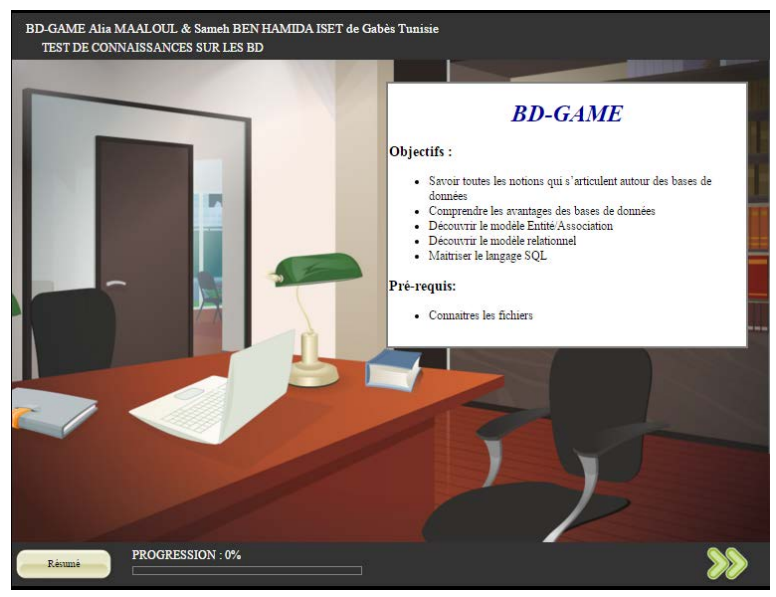

Figure 1. Example of a figure caption (BD-GAME).

\subsubsection{Implementation Approach}

The terms of use of the serious game at our educational sessions and outside these sessions are described in the following configurations:

- Use in group or whole class in video projection mode to present the game to students or to discuss with them certain concepts;

- In pairs, individually, collectively and how to revise the proposed within the game exercises;

- Ongoing, Tutorials, in individual support;

- And use as an educational activity learning and self-evaluation by the students alone outside the sessions of the course.

We report that we project BD-GAME to present him for students and to introduce them to its discovery and use. However, usage in pairs or in groups or alone account for almost most of the terms of use.

\subsubsection{Evaluation Method}

The most important thing is not to show that a given game has an overall positive effect, but to analyze where the positive effects are, negative or zero of a game and especially to link these effects to the conditions of the game. The effects are sought in the experience of students through their performance, their development skills, perceptions and their commitment (Chiousse, 2001).

An initial assessment stage had been completed at the end of the school year 2014-2015, based on results of a questionnaire administered to students and experimenters also from a series of interviews with other teachers. However, we studied:

- The degree of student satisfaction with regard to the use of BD-GAME;

- The perception of student's motivation to use the BD-GAME;

- The Difficulties of using the BD-GAME;

- The impact of the use of the BD-GAME on understanding the concepts related to the database course;

- The degree of acceptability of the BD-GAME by students;

- The degree of usability of the BD-GAME in the revision of the database field;

- The utility of using BD-GAME;

- Any BD-GAME improvements suggestions.

\subsubsection{Summary of Experience}

\section{Contributions}

According to the results of the questionnaire described above, this experiment was rich and flourishing. Indeed, the use of this tool has shown a high degree of motivation among student's testers as the playful side of the game to draw the attention of users through the presence of a set of attractive characters with fun animations. These results come join the achievements Muratet et al. (2011) relating to the assessment of a serious game for learning programming.

In addition, we also found a high degree of satisfaction of our students regarding the use of BD-GAME and 
we hope to continue to evolve according to their proposals mainly concern the necessity of adding sound to our BD-GAME in order to attract the attention of the user. They also suggested adding other characters in the game and this to avoid monotony.

Also, 93\% of students testers have found that using the BD-Game have allowed better learning and understanding of Data Base material.

In addition, $69 \%$ of students testers found that using the BD-GAME is easy and this will have an effect on the acceptability of this game by them. In contrast to the remaining $31 \%$, the acceptability of the game will not be systematic since it requires a learning step and familiarization with the tool and also $88 \%$ of students found that the BD-GAME has met their expectations which will facilitate their acceptance of this tool.

\section{Limits}

\section{Students' side}

- $31 \%$ of students felt that the acceptability of the game will not be systematic since it requires a learning step and familiarization with the tool.

- Other reported that they have experienced connection problems when BD-GAME used outside the classroom.

- Also, there are students who have requested more exercises.

Teachers and developers of serious games side

- The feedback to be given to students based on their actions constitutes a significant problem in general games.

- Also, environmental design requires an interface for tutors to encourage their immersion (Aoun et al., 2015).

- Furthermore, one of the major challenges that the designer must face is the delicate balance between the pleasure of the game and the seriousness of objectives.

\subsection{Experiment 2: The Flipped Classroom Teaching}

\subsubsection{Definition}

The flipped classroom is a pedagogical model in which the typical lecture and homework elements of a course are reversed (Educause Learning Intiative, 2012). It's a pedagogical approach that reverses the nature of learning activities in the classroom and at home, causing a change in the traditional learning roles. In other words, classroom activities become more attractive to learners as they become actors of their learning. It is not the teacher who brings knowledge, but it is the learner himself who goes in search of knowledge.

\subsubsection{Motivation, Context and Target Audience}

Always with the objective of promoting learning using new techno-pedagogical approaches we tested another teaching strategy that is the flipped classroom. In this experiment, we have tried to change the method of learning, in fact we spent a transmissive learning to active learning using the flipped classroom strategy by reversing the mode of teaching by mixing between the face-to-face and computer-mediated activities and organizational perspective by redistributing the learning time, the role of the teacher is then to support students in developing complex tasks. This cleared classroom time can be used for other activities based on learning. This experience is offered to students in the second year of the Science and Technology Department of Information and Communication of IHTS of Gabes for the DBMS course during a semester.

\subsubsection{Objectives}

Towards an improved learning, we set the following objectives:

- Involve students in the learning process;

- Promote collaborative work;

- To introduce students to the technological tools that can facilitate their learning;

- Giving meaning to the presence;

- Improving student learning in the subject taught;

- Having motivated students;

- Stimulate student engagement.

\subsubsection{Teaching Device}

This is to make students work upstream of the course, to devote the time they are present with the teacher to other activities: clarify certain concepts, answering student's questions, following presentations of students, ex- 
changes and debates. For this we have prepared a set of teaching resources that are made available to learners to view the upstream of the-face session will be dedicated to the discussion and explanation of concepts not included. A set of collaborative activities is also proposed to learners who collaborate with peers via the platform up to them (we used Espace). Finally viewing the course, each student must meet the QUIZ proposed for this purpose (we used Evalbox) which will be used for the teacher to assess the level of understanding of the course and better target difficult or ambiguous parts.

\subsubsection{Implementation Approach}

To ensure the flipped classroom strategy we defined a learning scenario that is divided into two phases: computer-mediated phase and one for the face-to-face phase.

Computer-mediated phase: a set of “capsules”, PowerPoint presentations and PDF documents are presented to students each at the appropriate time in the device used for computer-mediated part. For this, we used Espace as a collaborative learning platform, where we shared the different tutorials and instructions to see and read by students at home before coming to class for discussion. Figure 2 shows an example of team space on the platform Espace seen by the guardian teacher. A quiz (using Evalbox) is available for students to measure the degree of understanding and mastery of the concepts presented in the course materials.

The content will remain accessible all the time in the group for the revisions, exams and remediation in case of lack of understanding of the concept presented; follows each learner at their own pace.

Face-to-face phase: different activities were proposed: resolution of exercises, presentation, etc. In this phase, students are more involved in their learning process as it is to apply the principles of pedagogy work. These activities can be individual or group: thus promoting collaborative work.

Building on the results of the quiz, there was no explanation of the included parts of the course taken by students at home, as there were answers to questions of learners trying to involve everyone: the students are more engaged in their learning.

\subsubsection{Evaluation of the Experiment}

We come now to the evaluation of our hybrid training in two views: learner and an observer. This according to three criteria: pedagogical, organizational and technical.

First, we administered a questionnaire to learners to measure their degree of organizational standpoint of satisfaction, technical and pedagogical (Bernatchez, 2005).

From a pedagogical perspective we asked learners about the difficulty of training while 50\% of surveyed said that training is difficult while $45 \%$ did not agree on this view, and $5 \%$ are held by answer.

These results were predictable view that the device is new to organizational perspective learners alternating the distanciel and face-technique using different new tools (Espace, Evalbox) and various forms of course (video, pdf,...) and teaching by involving them in the learning process and using a new strategy, that of the flipped classroom. These changes disrupt the habits of learners and round a little reluctant to such an experience.

This experience is considered motivating by $75 \%$ of surveyed, while only $25 \%$ said it was not. Expectations for learners $60 \%$ said that the training met their expectations while $37 \%$ found no and $3 \%$ did not answer this question.

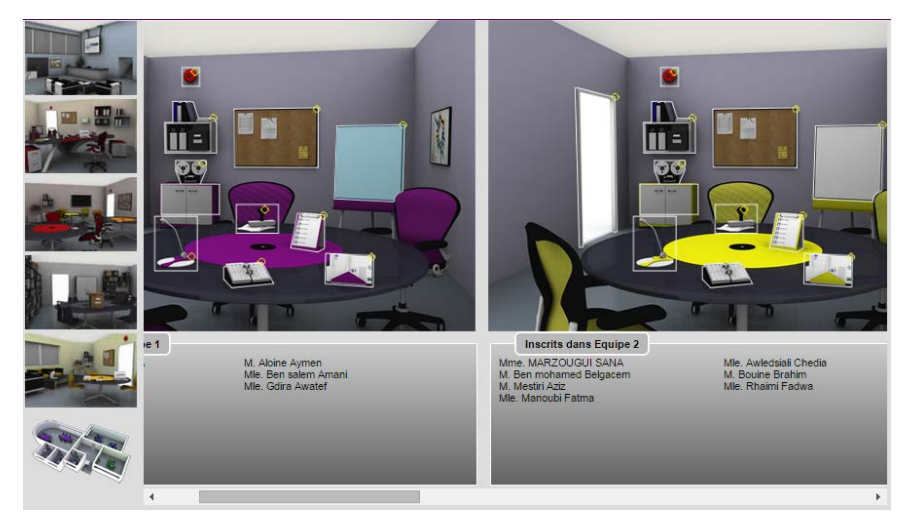

Figure 2. Example of a figure of a team space. 
$68 \%$ of surveyed reported they have found that the content of the training was clear while $23 \%$ disagreed and $9 \%$ did not answer this question.

These results are explained by the presentation of a simple course, structured and well detailed with lots of examples.

The problem situation is deemed clear for $73 \%$ of surveyed while only $23 \%$ were few agreements on the clarity of it.

$50 \%$ of surveyed do not agree on the usefulness of the forum for the understanding of the course, while only $46 \%$ of learners felt that the use of the forum promoted their learning and $4 \%$ have missed to answer this question.

These results are explained by the non-appropriation of the tool by most learners, for it had to book into the grip phase activity using the forum so that they better surround its usefulness.

To the question of tutor interventions were they beneficial to learning, $73 \%$ of surveyed agreed while only $27 \%$ have manifested their disagreement.

As for the diversification course materials used, $73 \%$ of surveyed expressed their agreement on the use of these different formats, while $27 \%$ expressed disagreement.

These results, how divergent, require us to devote more time to explain to learners the purpose of such experience and learn to be more involved in their learning.

We looked also to have the opinions of the testers learners on the organization of training and rectify any shortcomings in the next experiments.

To the question: Does the duration of the training was adequate; $68 \%$ agree that its duration was sufficient while $32 \%$ are not.

To follow the pace of work during training, $82 \%$ of learners are in total agreement followed the pace, but only $18 \%$ of learners felt that the pace was not appropriate.

$61 \%$ of testers found that the number and timing of synchronous meetings were very adequate.

Most testers learners (82\%) felt that the team organization has been effective and only $14 \%$ reported that they did not agree. $4 \%$ abstained to answer.

For answers on technical issues, 64\% of guinea pigs found easy access to platform while $36 \%$ found difficulty in access to it. This can be explained by the short period of ownership and the lack of experienced testers in the field of distance learning courses.

Only $46 \%$ of surveyed agreed on the proper functioning of all tools of the platform. This is explained by the non-operation of cat during synchronous meetings has been replaced by the use of the mail (for replies asynchronously) and awareness for synchronous responses.

These results, how divergent, require us to devote more time to the grip phase to ensure the adoption of the tool used well by almost all learners and that the objective of the training is identify good.

We also found that respondents are not willing to take initiative in their learning and they closely follow their teacher's instructions for this progressive preparation for the autonomy needed by offering activities where the level of involvement increases slowly.

Second, and in order to have a more objective opinion on the evaluation of the training we asked the support and advice of a teacher observer possessing good knowledge in the field of distance education. In what follows we give then the interpretations of the results of the questionnaire proposed by our observer classified aspects:

His observer views on pedagogical perspective that:

- The formulation of the objectives of the training is clear;

- The objectives are tailored to the target audience;

- The objectives are achievable in the time allotted to learning;

- There is coherence between the objectives and proposed activities;

- The course content is appropriate to the level of learners;

- The course content is well structured;

- The announced pedagogical method is applied;

- The content of the problem situation is clear;

- The proposed activities are consistent;

- The use of different forms of course materials is appreciated;

- Using Evalbox as evaluation software is especially useful for learners that it requires no prior learning;

- Using Evalbox as evaluation software is useful for the teacher to better target-face learning during the ses- 
sion.

The teacher observer states on organizational aspect:

- The expected scenario corresponds to that achieved;

- The constitution of the teams is balanced nevertheless its composition cannot be randomly (by affinity learners);

- The tutor's interventions have helped the progress of work of the participants;

- The technical problems encountered during the synchronous meetings have made it impossible to continue cats provided;

- Alternating between presential and distanciel can complete the training by reviewing the most difficult points and misunderstood by learners' distanciel.

- the duration of the experiment is sufficient

The teacher observer ahead of the technical aspects as:

- The style of presentation of the course is friendly;

- The plan explains the parts of the course;

- Access to the platform is easy;

- The handling of the platform is easy;

- The tools used in training were not all functional (chat).

\subsubsection{Summary of Experience}

\section{Contributions}

Experimenting with the flipped classroom strategy has shown a degree of satisfaction and significant learner motivation (75\%), as the majority of testers said they were agreements on the value of collaborative work; $73 \%$ reported that the proposal of several categories of courses was beneficial. Moreover, the majority of surveyed liked the new tools.

We then summarize the strengths of the experiment:

- A good atmosphere of collaboration to share the experience of peers;

- The use of video helps students in the review period to re-see the poorly understood sequences;

- The use of Evalbox can evaluate themselves;

- The involvement in the work promotes learning.

Limitations

- Only half of the students found that the use of the forum was needed, which is explained by the non-appropriation of this tool;

- Only 55\% felt that the alternating face-to-face learning and Computer-mediated learning was beneficial;

- The use of the platform was difficult for some learners;

- Meeting of technical problems (chat);

- connection problem (at home);

- Double Load (presence and distance).

\section{Summary and Comparison of Different Strategies}

Table 1 summarizes the various criteria of comparison between the two strategies used and this on several levels, namely educational criteria, technical criteria and organizational criteria.

Finally our comparative study, we present the issues favoring the techno-innovation and those that inhibits (Ben Salah, 2009).

\subsection{The Determinants of the Success of the Introduction of New Techno-Pedagogical Approaches}

As factors favoring the success of the introduction of new techno-pedagogical approaches we were able to identify the following:

- The involvement, commitment, motivation and collaboration of students, their willingness to change and acceptance of change.

- Participation and association of users from the outset and be active listening throughout the training.

- Switch to the gradual change in the teacher's and student habits. 
Table 1. Table of comparison of different strategies.

\begin{tabular}{|c|c|c|}
\hline & flipped classroom & serious game \\
\hline $\begin{array}{l}\text { Pedagogical criteria } \\
\text { - Learning type } \\
\text { of learners: motivation and } \\
\text { satisfaction } \\
\text { - Expected benefits on the side } \\
\text { of the teacher: } \\
\text { - Role of the learner } \\
\text { - role of the teacher } \\
\text { - Features }\end{array}$ & $\begin{array}{l}\text { Interactive learning and collaborative } \\
\text {-The Use of different forms of course materials } \\
\text { is beneficial: re-meet the expectations of all } \\
\text { students } \\
\text {-Using Evalbox is useful for self-assessment by } \\
\text { learners and to allow each student to follow his } \\
\text { pace of learning (have an always available } \\
\text { support) } \\
\text {-Need a commitment on the part of the learners } \\
\text { for the successful-face session (they must have } \\
\text { completed the distance learning): Learning } \\
\text { actor of his learning } \\
\text {-Teacher can better target-face to face learning } \\
\text { during the session } \\
\text {-Change the role of the teacher (tutor, } \\
\text { facilitator) } \\
\text {-Estimated training a little difficult }\end{array}$ & $\begin{array}{l}\text { Custom interactive learning and relevant } \\
\text {-The contribution of the student is substantial in terms } \\
\text { of motivation, satisfaction, better understanding, } \\
\text { better conditions for learning and enthusiasm. } \\
\text {-For the teacher, it allows him to innovate, raise the } \\
\text { interest of learners and promote their learning. } \\
\text {-Change the role of the learner becomes active and } \\
\text { leading actor of his apprenticeship wearing the cap of } \\
\text { a player seriously motivated and having the } \\
\text { opportunity to train and evaluate themselves with a } \\
\text { custom pattern in its capabilities and performance } \\
\text {-The changing role of the teacher (designer and } \\
\text { companion in the discovery phase of the game) } \\
\text {-Playfulness training }\end{array}$ \\
\hline $\begin{array}{l}\text { Technical criteria } \\
\text { - Tools and platforms used for } \\
\text { learning and for the evaluation } \\
\text { - Technical problems }\end{array}$ & $\begin{array}{l}\text {-Espace and Evalbox } \\
\text {-Possibilities of technical problems } \\
\text {-The non-appropriation of the tools used can be } \\
\text { a problem learning hence the need for handling } \\
\text { phase }\end{array}$ & $\begin{array}{l}\text {-BD-GAME } \\
\text {-Possibility of internet connection of technical } \\
\text { problems since the game is hosted in the cloud. }\end{array}$ \\
\hline $\begin{array}{l}\text { Organizational criteria } \\
\text { - distribution presence/distance } \\
\text { - Additional workload } \\
\text { - Human resources in terms of } \\
\text { roles and volume. }\end{array}$ & $\begin{array}{l}\text {-Alternating between the face-to-face and } \\
\text { computer-mediated learning can complete the } \\
\text { training by reviewing the most difficult points } \\
\text { and misunderstood by learners at home } \\
\text {-The constitution of the team promotes } \\
\text { collaborative work nevertheless its composition } \\
\text { cannot be randomly (by affinity learners) }\end{array}$ & $\begin{array}{l}\text {-Learning with BD-GAME is performed in and/or out } \\
\text { of the classroom } \\
\text { with or without the accompaniment of the teacher } \\
\text {-The workload is tolerable } \\
\text {-The training is flexible in terms of schedules } \\
\text { selected } \\
\text {-In tutorials and practical work, the vocation is done } \\
\text { in groups of learners }\end{array}$ \\
\hline
\end{tabular}

\subsection{The Brakes of Innovation}

The inhibitor factors impact on the appropriation of new techno-pedagogical approaches, according to our student and evaluators teachers, are attached to the approach itself, learners and the institutional environment.

Among the causes cited by the inhibitory questioned we mention:

- The abrupt change in the habits of learners;

- Poor communication of the objectives of the approach to be tested;

- Lack of resources and récurents technical problems (internet connection, PC...);

- Before a commissioning of the technological prowess at the expense of educational objective.

\section{Conclusion and Recommendations}

"The human world is not a large tool chest in which people are technical-made to meet their needs" Tardif \& Karsenti (2001: p. 90).

Given the various methods described and analyzed, we design increasingly it does not remain any teaching made and still valid. Indeed, teaching methods within the scope of "action sciences", which we know can never be fully modeled.

It is however possible to guarantee a number of recommendations of the success of a training and a successful learning process (Chiousse, 2001). These recommendations are often based on examples of good practice or good initiatives that have been identified and also involve external variables in the learning process but the acting on it. Therefore we recommend:

- Conducting a gradual change in the habits of learners so that they are involved in the learning process and that they are not overwhelmed by a sudden change;

- Having motivated individuals to learn and be formed by involving them in the choice of strategies to adopt and explaining the objectives of the process to be undertaken; 
- Having resource persons to guide the individual and guide his steps and be attentive learners throughout the learning process;

- Considering the diversity of public means, among other things, that the learning and promotion of training should not only concern the weakest or the already formed;

- Systematic and regular evaluations of the measures in place as well conduct behavior-health reform or readjust policies in place if necessary;

- Providing appropriate training in learners and meeting their expectations;

- Adapting to the learning situation and the personality of individuals;

- Providing training according to the needs of learners instead of following conventional learning;

- Clearly defining the objectives of the training;

- What training and its aims are well accepted in relation to the expectations of learners;

- Giving rise to a visible result, sensitive and recognized;

- Providing a backup solution in case of technical problems;

- Obtaining the necessary resources for successful training.

We also wish to point out that there is not a ready recipe for promoting learning, yet we must remain attentive to the learners and adjust the strategy to align the expectations of the latter. Therefore, before starting the introduction of new pedagogical approaches, we must first introduce learners to be elements involved in their learning, gradually involving them in the learning process.

Indeed, as said by Lebrun (2007: p. 19): "talking about the efficiency of an educational tool needs to refer to the methods in which this tool... to sit and educational objectives that underlie."

\section{Acknowledgements}

We would like to warmly thank our students for their active participation and our colleagues for their cooperation.

\section{References}

Aoun, A. Bret, M., Jacob, M., \& Roussel, B. (2013). The Flipped Classroom or Reorganization of Space-Time in Duality Paradigm “Teach/Learn”. http://blogs.univ-tlse2.fr/pedagotice/files/2013/09/24 aoun bret jacob roussel-versionfinale.pdf

Basque, J. (2007). The Development of the Teaching Scenario. Text from the EDU 1030 Educational Design Courses in Adult Education. Montreal: Télé-Université.

https://wiki.umontreal.ca/download/attachments/78513937/TEXTE-441_UdeM.pdf

Bédard, D., \& Béchard, J. P. (2009). Innovation in Higher Education. Paris, France: University Press of France.

Ben Salah, B. (2009). Introduction Techno Innovation in Educational/Training Institutions in Francophone Countries: Representations of the Initiators Players.

Bernatchez, P. A. (2005). Towards a Typology of Managerial Activities and Role of Guardians, Quebec Review Board of Distance Education.

Chiousse, S. (2001). Pedagogy and Adult Learning Status and Recommendations.

Educause Learning Intiative (2012). Things You Should Know About... Flipped Classrooms. https://net.educause.edu/ir/library/pdf/ELI7081.pdf

Joyce, B., Weil, M., \& Calhoun, E. (2004). Models of Teaching (7th ed.). Boston: Allyn and Bacon.

Kirkpatrick, D. L. (2007). The Four Level of Evaluation. Info Line 0701, 1-16.

Lebrun, M. (2007). Theory and Methods for Teaching and Learning (2nd ed.). Brussels: De Boeck Université.

Legendre, M. F. (2004). Cognitivism and Social Constructivism: The Theoretical Foundations for Their Use in the Development and Implementation of the New Training Program. In P. Jonnaert, \& A. M’Batika (Eds.), The Curricular Reforms: Viewpoints (pp. 15-47). Quebec: University Press of Quebec.

Legendre, R. (2005). Current Dictionary of Education (3rd ed.). Montreal: Guerin.

Meirieu, P., Develay, M., Durand, C., \& Mariani, Y. (1996). Knowledge Transfer in Initial Training and Continuing Education. Lyon: CRDP.

Muratet, M., Torgue, O., Viallet, F., \& Jessel, J. P. (2011). Evaluation of a Serious Game for Programming Learning. Artificial Intelligence Review, 25, 175-202. http://dx.doi.org/10.3166/ria.25.175-202 
Panis, A. (2009). Realization of a Learning Courseware Prototype of the Concept of Amortization for First Class G2. Master's Thesis, Yaoundé: University of Yaounde I (M1415). http://adelaide-pani.over-blog.com/article-34765347.html

Paquette, G., Aubin, C., \& Crevier, F. (1998). Method of Learning Engineering (MISA), Engineering Guide (Version 2.1). Québec: LICEF Research Center, Télé-université, 290.

Poumay, M. (2014). Six Levers for Improving Student Learning in Higher Education. International Review of Education of Higher Education, 30-31. http://ripes.revues.org/778

Pratt, D. D. (2005). Five Perspectives on Teaching in Adult and Higher Education. Malabar, FL: Krieger Publishing Company.

Sanchez, É., Ney, M., \& Labat, J.-M. (2011). Serious and University Teaching Games: From Design to the Evaluation of Learning-International Review of Technologies in University Teaching. http://www.ritpu.org/IMG/pdf/RITPU_v08_n01-02_48.pdf

Tardif, M., \& Karsenti, T. (2001). Technologies and Pedagogical Foundations of Communication. In T. Karsenti, \& F. Larose (Eds.), ICT... in the Heart of University Pedagogy (pp. 89-115). Québec: Presses de l’Université du Québec.

Tremblay-Wragg, E. (2014). Use a Variety of Teaching Models, the Table: Exchange of Good Practices between University Teachers. Volume 3, Special Issue.

Viau, R. (2006). The Motivation of University Students: A Better Understanding for Better Action. 